\title{
Preparation and Characterization of Inulin Coated Gold Nanoparticles for Selective Delivery of Doxorubicin to Breast Cancer Cells
}

\author{
Mariano Licciardi, ${ }^{1,2}$ Anna Li Volsi, ${ }^{1}$ Nicolò Mauro, ${ }^{1}$ Cinzia Scialabba, ${ }^{1}$ \\ Gennara Cavallaro, ${ }^{1}$ and Gaetano Giammona ${ }^{1,2}$ \\ ${ }^{1}$ Dipartimento di Scienze e Tecnologie Biologiche, Chimiche e Farmaceutiche (STEBICEF), University of Palermo, \\ Via Archirafi 32, 90123 Palermo, Italy \\ ${ }^{2}$ Mediterranean Center for Human Health Advanced Biotechnologies (CHAB), ATeN Center, University of Palermo, Palermo, Italy
}

Correspondence should be addressed to Mariano Licciardi; mariano.licciardi@unipa.it

Received 10 March 2016; Accepted 9 June 2016

Academic Editor: Ovidiu Ersen

Copyright ( $(2016$ Mariano Licciardi et al. This is an open access article distributed under the Creative Commons Attribution License, which permits unrestricted use, distribution, and reproduction in any medium, provided the original work is properly cited.

\begin{abstract}
A novel folate-targeted gold-based nanosystem for achieving selectivity towards folate receptor (FR) positive cells is proposed, by virtue of the fact that the FR is a molecularly targeted entity overexpressed in a wide spectrum of solid tumors. A new inulin-folate derivative (INU-FA) has been synthesized to act as coating agent for $40 \mathrm{~nm}$ gold nanoparticles. The obtained polymer-coated gold nanoparticles (Au@INU-FA) were characterized in terms of hydrodynamic radius, shape, zeta potential, and aqueous stability and were loaded with doxorubicin (Au@INU-FA/Doxo). Its release capability was tested in different release media. The selectivity of Au@INU-FA/Doxo system towards FRs-positive cancer cells was proved by the differences in the quantitative uptake using human breast cancer MCF7 as FR-positive cells and 16HBE epithelial as noncancer cell line. Furthermore, the folate-mediated uptake mechanism was studied by FRs-blocking experiments. On the whole Au@INU-FA/Doxo was able to be preferentially internalized into MCF7 cells proving a folate-mediated endocytosis mechanism which allowed a higher and selective cytotoxic effect towards cancer cells. The cytotoxicity profile was evaluated on both cancer and noncancer cell lines, displaying that folate-mediated targeting implied advantageous therapeutic effects, such as amplified drug uptake and increased anticancer activity towards MCF7 cancer cells.
\end{abstract}

\section{Introduction}

Cancer is one of the most important human diseases, being the leading cause of mortality in the modern world, and therefore has received significant attention focused on finding new therapeutics [1]. Conventional therapy methods in cancer, such as chemotherapy, radiation, and surgery, involve the employment of agents that do not greatly differentiate between cancerous and normal cells, leading to systemic toxicity and severe side effects. As a matter of fact, the effectiveness of many anticancer drugs is limited due to the inability to reach the target site in sufficient concentration and to efficiently exert the pharmacological effect without causing irreversible unwanted injury to healthy tissues and cells [2]. In contrast to conventional approaches, nanotechnologies may offer a less-invasive alternative, based on the development of nanoscale tumor-targeted delivery systems that allow tumorselective drug delivery by both passive and active targeting [3], thus reducing nonspecific cytotoxicity and enhancing the life expectancy and quality of life of the patient [4]. Molecularly targeted therapy emerged as an effective approach to overcome the lack of specificity of conventional chemotherapeutic agents [5]. Different nanostructured drug delivery systems using a variety of engineered materials including polymers (polymeric nanoparticles, micelles, or dendrimers) [6-8], lipids (liposomes) [9], viruses (viral nanoparticles) [10], organometallic compounds, and metallic nanoparticles have been developed [11]. Among these, gold nanoparticles (GNPs) have emerged as promising carriers for drug delivery applications. In particular, GNPs offer several advantages 
for biomedicine being versatile agents with unique optical (Surface Plasmon Resonance; SPR) and physicochemical properties [12]. They have been extensively used as drug delivery systems and as highly sensitive diagnostic tools as well as hyperthermia agents depending on their tunable shape, size, and composition. Recently, the preparation of polymer-functionalized GNPs has attracted increasing interest not only to improve the stability of nanoparticles in physiological media but also to modify the surface properties of nanoparticles. For example, bioconjugation of GNPs with targeting groups for active tumor targeting has been achieved due to the high binding affinity of gold for thiol groups [13].

Moreover, in vivo applications of GNPs require polymeric coatings to ensure high physicochemical stability and biocompatibility. A wide variety of biocompatible polymers that might perform these coating functions have been investigated, including natural and synthetic polymers [14, 15]. The coating polymers must satisfy some requirements such as ensuring long-term stability of GNPs in aqueous media and preventing their aggregation in different body districts. Moreover coated GNPs should guarantee a prolonged blood circulation time and provide active functional groups useful to conjugate targeting ligands to GNPs surface. Our group has synthetized many polymeric materials that may be used to coat metallic nanoparticles, including synthetic polyamino acid derivatives [16] and polysaccharides based constructs $[17,18]$. Among them, inulin, a natural, biocompatible, and biodegradable polysaccharide consisting of linear chains of $\beta$-(2-1) fructose units that exhibit many hydroxyl functional groups that make inulin versatile and easy to functionalize, has been employed as coating agent for metal NPs and used in several biomedical applications [17-24]. One of the strategies to achieve cancer specificity is to conjugate targeting ligands to the polymeric coating of GNPs. Then, the targeting molecule should be able to recognize and bind a specific receptor on the target cell surface to induce selective internalization of the system. Among targeting ligands, there is the vitamin folic acid (FA). Folate receptors (FRs) are selectively overexpressed on a wide spectrum of human cancer cells. Moreover, FA has a low molecular weight (Mr 441.4), high receptor affinity $\left(K_{d} \approx 10^{-10} \mathrm{M}\right)$, low immunogenicity, stability during storage, ease of modification, compatibility with a variety of organic and aqueous solvents, and low cost and is readily available $[25,26]$. For example, in a recent work carried out by Banu et al. gold nanoparticles loaded with doxorubicin have been functionalized with folic acid to achieve selectivity towards MDA-MB-231 breast cancer cells [27].

In this work folic acid was chemically conjugated via amide bond to the backbone of an inulin amino-derivative. Taking advantage of the well-known chemical reactivity of thiol and amino groups with gold surfaces, the new inulinfolate conjugate derivative, INU-FA, was used to successfully functionalize the surface of $40 \mathrm{~nm}$ gold nanospheres. In particular, the interactions between the available amino pendant groups of INU-FA and gold nanoparticles were exploited to stabilize gold nanoparticles. Although thiol groups have a stronger affinity to the gold particles surface compared to amino groups, from a synthetic point of view, the experimental conditions of amino-functionalized
Preferential uptake and selective cytotoxic effect of Au@INU-FA/Doxo towards cancer cells

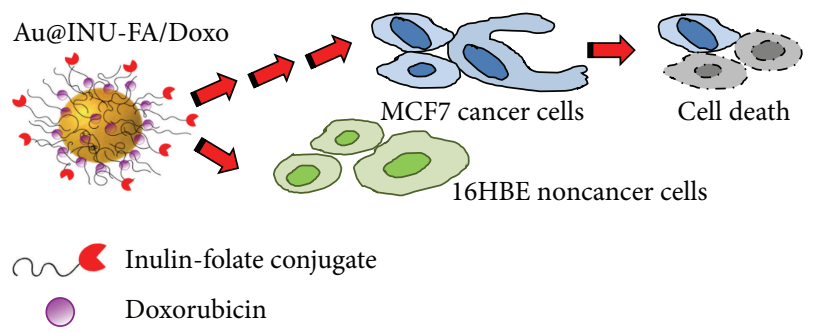

FIGURE 1: Schematic illustration of the selective cytotoxic effect of Au@INU-FA/Doxo on MCF7 cancer cells, expressing high levels of FRs, compared with normal human bronchial epithelial cells $16 \mathrm{HBE}$.

copolymers are more advantageous than thiolated polymers, not being necessary complicated experimental procedures such as the precise control of $\mathrm{pH}$ of the reaction and the total absence of oxygen in the reaction environment to avoid disulfur formation and, as a consequence, polymer crosslink. As additional advantage, amino-functionalized copolymers are endowed with a long-term stability, maintaining their chemical characteristics unaltered.

The obtained system, henceforth named Au@INU-FA/ Doxo, was able to load doxorubicin while showing excellent physiochemical stability. By using blocking receptors experiments we demonstrated the folate-mediated uptake of Au@INU-FA/Doxo into FRs-positive human breast cancer cells MCF7 (Figure 1). Moreover we proved that the conjugation of folate onto inulin backbone enhanced the selective drug accumulation into MCF7 cells, expressing high levels of FRs, compared with normal human bronchial epithelial cells $(16 \mathrm{HBE})$, thereby resulting in a marked higher cytotoxicity towards cancer cells.

\section{Materials and Methods}

2.1. Materials. Inulin-2-aminoethyl-carbamate (INU-EDA), used as a starting copolymer, was synthetized as previously reported [24]. Inulin, ethylenediamine (EDA), bis(4nitrophenyl)carbonate (BNPC), gold chloride trihydrate $\left(\mathrm{HAuCl}_{4} \quad 3 \mathrm{H}_{2} \mathrm{O}\right)$, sodium citrate tribasic dihydrate, $\mathrm{N}$ ethyl- $\mathrm{N}^{\prime}$-(3-dimethylaminopropyl)carbodiimide hydrochloride (EDC-HCl), N-hydroxysuccinimide (NHS), and bicinchoninic acid kit for protein determination, were purchased from Aldrich. Sephadex G-15 and anhydrous dimethylformamide (DMF) were purchased from Fluka (Switzerland). All reagents were of analytic grade, unless otherwise stated. The ${ }^{1} \mathrm{H}$ NMR spectra were recorded using a Bruker Avance II 300, spectrometer operating at $300 \mathrm{MHz}$. Size exclusion chromatography (SEC) was carried out using a Phenomenex PolySep-GFC-P3000 column (California, USA) connected to a Waters 2410 refractive index detector. $\mathrm{DMF}+\mathrm{LiBr}$ $0.1 \%$ solution was used as an eluent at $60^{\circ} \mathrm{C}$ with a flow rate of $0.6 \mathrm{~mL} \mathrm{~min}^{-1}$, sample concentration $2.5 \mathrm{mg} / \mathrm{mL}$. Poly(ethylene oxide) standards (range $10-1.5 \mathrm{kDa}$ ) were used to set up calibration curve. 
2.2. Synthesis of Gold Nanoparticles GNPs (Au@citrate). Citrate stabilized $40 \mathrm{~nm}$ GNPs with a spherical shape and a narrow size distribution were synthetized via the reduction of $\mathrm{HAuCL}_{4}$ by sodium citrate [28].

2.3. Synthesis of INU-EDA-Folate Copolymer (INU-FA). Inulin-2-aminoethyl-carbamate (INU-EDA), with a derivatization degree of pendant primary amine groups $\left(\mathrm{DD}_{\mathrm{EDA}}\right)$ of $25 \mathrm{~mol} \%$ related to inulin monomeric units was used as starting copolymer [20]. A proper amount of folic acid (143.9 mg, $0.326 \mathrm{mmol}$ ) was solubilized in Milli-Q water at $\mathrm{pH} 7.02$, and then NHS $(56.24 \mathrm{mg}, 0.488 \mathrm{mmol}$ ) and EDC$\mathrm{HCl}(93.68 \mathrm{~g}, 4.88 \mathrm{mmol}$ ) powders were added to the reactive mixture adjusting the $\mathrm{pH}$ at 7.02. The resulting solution was added to $2 \mathrm{~mL}$ of a INU-EDA solution in Milli-Q water (200 mg, $1.086 \mathrm{mmol}$ of amino pendant groups) drop-wise and left to react at $25^{\circ} \mathrm{C}$ for $18 \mathrm{~h}$. The INU-FA conjugate was then purified by gel filtration chromatography using Sephadex G-15 as separating gel. Then the INU-FA solution was freeze-dried from water; the pure product was obtained with $88 \% \mathrm{w} / \mathrm{w}$ yield based on the starting inulin $(176 \mathrm{mg}$ of INU-FA product starting from $200 \mathrm{mg}$ of the starting inulin). Size exclusion chromatography (SEC): $\mathrm{Mw} 6784, \mathrm{Mw} / \mathrm{Mn}$ 1.24. ${ }^{1} \mathrm{H}$ NMR $\left(300 \mathrm{MHz}, \mathrm{D}_{2} \mathrm{O}\right): \delta 2.90-3.40\left(4 \mathrm{H}_{\mathrm{EDA}}\right.$, $-\mathrm{NH}-$ $\left.\mathbf{C H}_{2}-\mathrm{CH}_{2}-\mathrm{NH}_{2}\right), 3.60-3.90\left(5 \mathrm{H}_{\mathrm{INU}},-\mathrm{CH}_{2}-\mathrm{OH} ;-\mathbf{C H}-\mathrm{CH}_{2}-\right.$ $\mathrm{OH}$; -C- $\left.\mathrm{CH}_{2}-\mathrm{O}-\right)$, 3.92-4.30 (2H $\mathrm{H}_{\mathrm{INU}}$, -C-CH-OH; - $\left.\mathrm{CH}-\mathrm{OH}\right)$, $\delta 7.517-6.685\left(4 \mathrm{H}_{\mathrm{FA}}\right.$, phenyl group).

2.4. Preparation of INU-FA and INU-FA/Doxo Functionalized GNPs. A solution of INU-FA copolymer $(952.5 \mu \mathrm{L}$, $250 \mu \mathrm{g} / \mathrm{mL}$ ), treated with $2 \mu \mathrm{L}$ of TEA, was added to the citrate capped GNPs (Au@citrate), at a ratio of $10 \mathrm{INU}$ EDA-FA/Au $\mathrm{nm}^{2}$. The mixture was incubated for $30 \mathrm{~min}$ at room temperature. Coated particles (Au@INU-FA) were then washed twice by centrifugation at $2760 \mathrm{~g}(20 \mathrm{~min}$, $\left.25^{\circ} \mathrm{C}\right)$ and stored at $4^{\circ} \mathrm{C}$ as colloidal dispersion $(150 \mu \mathrm{g} / \mathrm{mL}$ $\left.\mathrm{Au}^{0}\right)$. In these conditions, INU-FA coated nanoparticles maintain their physical-chemical properties unaltered for at least six months. For the preparation of doxorubicin loaded GNPs (Au@INU-FA/Doxo), $60 \mu \mathrm{L}$ of an aqueous doxorubicin hydrochloride solution $1 \mathrm{mg} / \mathrm{mL}$, previously treated with TEA $\left(1 \mu \mathrm{L}, 0.7 \times 10^{-2} \mathrm{mmol}\right)$, was added to INU-FA solution $(423 \mu \mathrm{L}, 250 \mu \mathrm{g} / \mathrm{mL})$. The obtained mixture was added to $1 \mathrm{~mL} 0.240 \mathrm{mg} / \mathrm{mL}$ of Au@citrate aqueous dispersion to obtain an $\mathrm{R} \mathrm{Au}^{0} /$ Doxo equal to $4 \mathrm{w} / \mathrm{w}$. After the incubation time (overnight, room temperature) the system was centrifuged $(20 \mathrm{~min}$, at $3.500 \mathrm{rpm})$ and washed twice in Milli-Q water to remove the excess of doxorubicin. Dynamic light scattering (DLS) data is as follows: Au@INUFA: $Z$ average $45.05 \mathrm{~nm}$, PDI 0.14 and $Z$ potential $-11.2 \mathrm{mV}$; Doxo/Au@INU-FA: $Z$ average: 40.7 nm, PDI 0.21, and Zeta potential: $-10.7 \mathrm{mV}$.

2.5. Determination of Drug Payload into Au@INU-FA/Doxo and Drug Release Studies. The amount of drug payload into Au@INU-FA/Doxo was measured by HPLC method. A precise amount of Au@INU-FA/Doxo was dispersed in Milli-Q water $\mathrm{pH}$ 4.5/ethanol 2:1 (v/v) to extract the loaded drug. After $2 \mathrm{~h}$ of extraction under stirring, the dispersion was centrifuged ( $20 \mathrm{~min}$, at $3.5000 \mathrm{rpm}$ ) and the supernatant was freeze-dried. Then the solid residue of the extracted drug was solubilized in the eluent used for HPLC analysis $\left(\left(\mathrm{NH}_{4}\right)_{2} \mathrm{HPO}_{4} 0.4 \mathrm{M} /\right.$ Acetonitrile $\left.68: 32 \mathrm{v} / \mathrm{v}\right)$, filtered on a cellulose regenerated filter, cut-off $0.2 \mu \mathrm{m}$, and injected in a $\mathrm{C}_{18}$ Gemini HPLC column. The content of drug loaded (DL) into the system was calculated by using a calibration curve obtained for serially diluted concentrations of doxorubicin in the eluent and expressed as the amount of loaded doxorubicin per unit mass of $\mathrm{Au}^{0}$. The DL resulted to be $18 \pm 2 \%$ $(\mathrm{w} / \mathrm{w})$, while the encapsulation efficiency was calculated to be $93 \pm 2 \%$. For drug release studies, an appropriate amount of Au@INU-FA/Doxo was placed in a dialysis membrane with a molecular weight cut-off of $12 \mathrm{KDa}$, immersed in $10 \mathrm{~mL}$ of $\mathrm{PBS}$ at $\mathrm{pH} 7.4$ and incubated at $37^{\circ} \mathrm{C}$ under continuous stirring. At scheduled time intervals, aliquots of external medium $(1 \mathrm{~mL})$ were withdrawn and replaced with an equal amount of fresh medium. The withdrawn samples were analyzed by HPLC to determine the amount of released drug. Release profiles were determined by comparing the amount of released drug as a function of incubation time with the total amount of drug loaded into the Au@INU-FA/Doxo. The same analysis was carried out using PBS pH 5.5 and all the release data were compared with the diffusion of doxorubicin alone (free base), obtained by using the same procedure. Data were corrected taking into account the dilution procedure.

2.6. Transmission Electron Microscopy (TEM). GNPs were visualized using a TEM JEOL JEM-1400PLUS $120 \mathrm{kV}$ TEM (Japan) equipped with GATAN US1000 CCD camera (2k $\times 2 \mathrm{k}) .10 \mu \mathrm{L}$ droplets of the sample were drop casted onto a piece of ultrathin Formvar-coated 200-mesh copper grid (Ted.pella, Inc) and left to dry in air.

2.7. UV-Vis Spectroscopy. UV-Visible spectra were recorded with a Shimadzu UV-2400 spectrophotometer. All samples (Au@citrate,Au@INU-FA, and Au@INU-FA/Doxo) were placed in a cell and spectral analysis was performed in the 400 to $800 \mathrm{~nm}$ range at room temperature. For the determination of the amount of folic acid linked in INUEDA, the absorbance of a weighted amount of INU-FA in Milli-Q water $\mathrm{pH} 8$ for $\mathrm{NaOH} 1 \mathrm{~N}$ at $364 \mathrm{~nm}$ was measured and this value was compared to that of a calibration curve obtained from standard solutions of folic acid in Milli-Q water $\mathrm{pH} 8$ for $\mathrm{NaOH} 1 \mathrm{~N}$ (concentration range from 0.003125 to $0.1 \mathrm{mg} \mathrm{mL}^{-1} ; R^{2}=0.998$ ).

2.8. Dynamic Light Scattering (DLS) Analysis and Zeta Potential Measurements. DLS studies and zeta potential measurements $(\mathrm{mV})$ were performed at $25^{\circ} \mathrm{C}$ using a Malvern Zetasizer Nano ZS instrument, fitted with a $532 \mathrm{~nm}$ laser at a fixed scattering angle of $173^{\circ}$. Aqueous solutions of Au@citrate, Au@INU-FA, and Au@INU-FA/Doxo $(0.015 \mathrm{mg} / \mathrm{mL})$ were analyzed. The intensity-average hydrodynamic diameter and polydispersity index (PDI) were obtained by cumulant analysis of the correlation function. The zeta potential $(\mathrm{mV})$ was calculated from the electrophoretic mobility using the Smoluchowski relationship and assuming that $K \cdot a \gg 1$ 
(where $K$ and $a$ are the Debye-Hückel parameter and particle radius, resp.).

2.9. Energy Dispersive X-Ray Analysis of the Surface of Au@INU-FA/Doxo. Qualitative elementary composition of freeze-dried Au@INU-FA/Doxo was obtained using a scanning electron microscope, ESEM Philips XL30. Samples were dusted on a double sided adhesive tape previously applied on a stainless steel stub prior to chemical elementary analysis.

2.10. Cell Cytotoxicity. Human breast cancer cells (MCF7) and human bronchial epithelial cells (16HBE) cells were purchased from Istituto Zooprofilattico Sperimentale della Lombardia e dell'Emilia Romagna (Italy). Cells were grown in Dulbecco's modified Eagle's medium (DMEM, Euroclone, Italy) with $10 \%$ fetal bovine serum (FBS) and $1 \%$ of penicillin/streptomycin $(100 \mathrm{U} / \mathrm{mL}$ penicillin and $100 \mathrm{mg} / \mathrm{mL}$ streptomycin), $1 \%$ glutamine, and $0.5 \%$ of amphotericin $\mathrm{B}$, at $37^{\circ} \mathrm{C}$ in $5 \% \mathrm{CO}_{2}$ humidified atmosphere.

The cytotoxicity was assessed by the MTS assay on MCF7 and 16HBE cells using MTS cell proliferation assay (Cell Titer 96 Aqueous One Solution, Promega, Italy). Cells were seeded in 96-well plate at a density of $2 \times 10^{4}$ cells/well and grown as reported above. After overnight attachment, the medium was replaced with $200 \mu \mathrm{L} /$ well of fresh cell medium containing empty Au@INU-FA and Au@INU-FA/Doxo at a concentration per well equal to $330,165,82.5,41.25$, and $20.62 \mu \mathrm{g} / \mathrm{mL}$ of $\mathrm{Au}^{0}$, corresponding to $100,50,25,12.5$, and $6.125 \mu \mathrm{M}$ of doxorubicin per well. After 4,24 , and $48 \mathrm{~h}$, supernatants were removed and a 1/20 dilution of MTS reagent in media was added to the wells $(120 \mu \mathrm{L} /$ well $)$ and incubated at $37^{\circ} \mathrm{C}$ for $2 \mathrm{~h}$. Then, the absorbance at $490 \mathrm{~nm}$ was measured using a microplate reader (Multiskan, Thermo, UK). Pure cell medium was used as a negative control. Results were expressed as percentage of the control cells. All culture experiments were performed in triplicate. Doxorubicin hydrochloride solutions at the same tested concentrations were used as a positive control.

2.11. Blocking Receptor Experiments. FA receptor (FR) blocking assay, followed by MTS assay, was performed on MCF7 as FRs overexpressing cells. A density of $2 \times 10^{4}$ cells per well, grown with a DMEM without folic acid, were seeded in a 96-well culture plate. After overnight attachment, the medium was replaced with $200 \mu \mathrm{L} /$ well of DMEM supplemented with $250 \mathrm{mg} / \mathrm{L}$ of folic acid to saturate FRs. After $3 \mathrm{~h}$ incubation time at $37^{\circ} \mathrm{C}$, the medium was replaced with $200 \mu \mathrm{L} /$ well of fresh cell medium containing Au@INUFA/Doxo at a concentration per well equal to $330,165,82.5$, 41.25 , and $20.62 \mu \mathrm{g} / \mathrm{mL}$ of $\mathrm{Au}^{0}$, corresponding to 100,50 , $25,12.5$, and $6.125 \mu \mathrm{M}$ of doxorubicin per well. After 4,24 , and $48 \mathrm{~h}$, supernatants were removed and MTS assay was carried out as reported above. Pure cell medium was used as a negative control. Results were expressed as percentage reduction of the control cells. All culture experiments were performed in triplicate. Doxorubicin hydrochloride solutions at the same concentrations were used as a positive control.
2.12. Au@INU-FA/Doxo Uptake Studies. MCF7 and 16HBE cell lines were seeded at a density of $2 \times 10^{4}$ cells/well and grown as reported above. After overnight attachment the medium was replaced with $200 \mu \mathrm{L}$ of fresh DMEM containing $\mathrm{Au} @ \mathrm{INU}-\mathrm{FA} / \mathrm{Doxo}$ at the concentration of $12 \mu \mathrm{g} / \mathrm{mL} \mathrm{Au} \mathrm{Au}^{0}$, corresponding to $5 \mu \mathrm{M}$ of doxorubicin, and cells were incubated for 30 minutes, $1 \mathrm{~h}$, and $2 \mathrm{~h}$. After each incubation period, the medium was removed and the cell monolayer was washed twice with DPBS and fixed with $4 \%$ formaldehyde for $30 \mathrm{~min}$. Subsequently, the formaldehyde solution was removed, the cells were washed with DPBS, and the nuclei were stained with 4',6-diamidino-2-phenylindole (DAPI). After 20 min incubation, DAPI solution was removed, the cells were washed three times with DPBS and observed by an Axio Vert.A1 fluorescence microscope (Zeiss). The images were recorded using an Axio Cam MRm (Zeiss).

For quantitative Au@INU-FA/Doxo uptake fluorescence analysis, after incubation, cells were lysed in $50 \mu \mathrm{L}$ lysis buffer (1\% Triton X-100, 2\% SDS in DPBS) at $37^{\circ} \mathrm{C} .25 \mu \mathrm{L}$ of lysates was transferred to disposable 96-well plates and diluted to $100 \mu \mathrm{L}$ with Milli-Q water for fluorescence intensity measurements ( $\left.\lambda_{\mathrm{EX}}: 490 \mathrm{~nm} ; \lambda_{\mathrm{EX}}: 580 \mathrm{~nm}\right)$ on an Eppendorf plate reader spectrofluorophotometer. The remaining $25 \mu \mathrm{L}$ of lysates were used to determine the protein content using the bicinchoninic acid kit for protein determination (Sigma Aldrich), according to the protocol of the manufacturer. For determination of the mean fluorescence intensity, fluorescent signals were corrected for the amount of protein in the samples. Free Doxorubicin (Doxo $\mathrm{HCl}$ ) $5 \mu \mathrm{M}$ was used as positive control for quantitative uptake fluorescence analysis. The experiment was carried out in triplicate.

2.13. Statistical Analysis. A $t$-test was applied to compare different sample groups. Data were considered statistically significant with a value of $p<0.05$. All values are the average of three experiments \pm standard deviation.

\section{Results and Discussions}

3.1. Synthesis of INU-FA Copolymer. Unregulated proliferation of cancer cells requires high consumption of folate for DNA replication, leading to a folate receptor (FR) overexpression in cancers like breast, ovary, uterus, colon, lung, and kidney cancer. In normal tissues, FRs are present in low or nondetectable quantities. These features have encouraged the synthesis of the new folate conjugate of inulin, INU-FA, here proposed as a coating agent for $40 \mathrm{~nm}$ gold nanospheres, in order to confer FR-mediated endocytosis properties to the nanosystem and to allow a higher and selective cytotoxic effect towards cancer cells. First of all, inulin was partially functionalized with EDA so as to introduce primary amine pendants that can be utilized as versatile functions allowing further derivatization. A derivatization degree in EDA of 25\% was obtained ( $\mathrm{DD}_{\mathrm{EDA}}$ related to inulin repeating units). In a second step, INU-EDA was functionalized with FA by amidic bond, using EDC and NHS as coupling agents, as shown in Scheme 1. The stoichiometric conditions employed were moles of FA/moles of amino pendant groups in INU-EDA $=0.3$; moles of EDC- $\mathrm{HCl} /$ moles of $\mathrm{FA}=1.5$; and moles of 


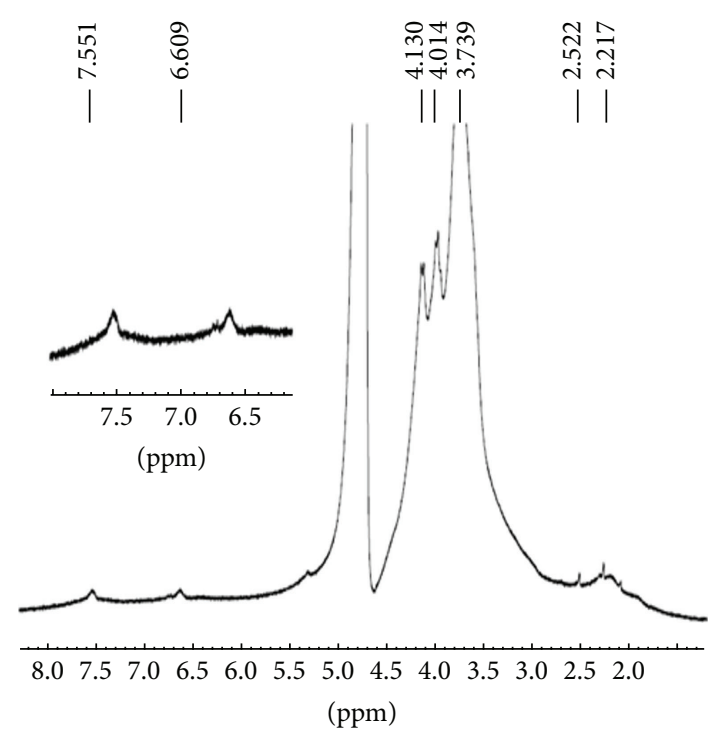

Figure $2:{ }^{1} \mathrm{H}$ NMR spectrum $\left(300 \mathrm{MHz}, \mathrm{D}_{2} \mathrm{O}\right)$ of INU-FA copolymer. Spectroscopic data are in agreement with attributed structure: $\delta$ 2.72-3.17 $\left(4 \mathrm{H}_{\mathrm{EDA}}\right.$, $\left.-\mathrm{NH}-\mathrm{CH}_{2}-\mathrm{CH}_{2}-\mathrm{NH}_{2}\right), 3.611-3.704\left(5 \mathrm{H}_{\mathrm{INU}},-\mathrm{CH}_{2}-\right.$ $\mathrm{OH}$; - $\mathrm{CH}-\mathrm{CH}_{2}-\mathrm{OH}$; -C- $\left.\mathrm{CH}_{2}-\mathrm{O}-\right), 3.99-4.12\left(2 \mathrm{H}_{\mathrm{INU}},-\mathrm{C}-\mathrm{CH}-\mathrm{OH}\right.$; $-\mathrm{CH}-\mathrm{OH}), 6.68-7.5\left(\mathrm{H}_{\mathrm{FA}}\right.$, aromatic ring).

NHS/moles of FA $=1.5$. The amount of folic acid linked to INU-EDA copolymer was measured by using two methods: ${ }^{1} \mathrm{H}$ NMR and UV spectroscopies. The ${ }^{1} \mathrm{H}$ NMR allowed an easy quantification of the FA molecules linked to inulin (Figure 2), by comparing the integrals of the peak at $\delta 7.52-$ 6.69 , ascribable to the protons of the phenyl ring of FA, to those at $\delta 3.55-4.19$ belonging to the protons of INU backbone. The molar percent of FA covalently linked to inulin $\left(\mathrm{DD}_{\mathrm{FA}} \%\right)$ was also determined by means of UV spectroscopy, measuring the absorbance of a weighted amount of INUFA in Milli-Q water pH 8 for $\mathrm{NaOH} 1 \mathrm{~N}$ at $\lambda 364 \mathrm{~nm}$, and comparing this value to that of a calibration curve obtained from standard solutions of folic acid in the same solvent. The average of $\mathrm{FA}$ derivatization degree $\left(\mathrm{DD}_{\mathrm{FA}} \%\right)$ calculated by means of ${ }^{1} \mathrm{H}$ NMR and UV spectroscopies resulted equal to $5.45 \mathrm{~mol} \%$ referred to the inulin repeating units. The INUFA conjugate still maintains a large number of primary amine groups available for the subsequent coating of GNPs trough covalent bond. Relative weight, average molecular weight $(\mathrm{Mw})$, and polydispersity of the synthetized copolymers were determined by SEC analyses and data are reported in Table 1. The molecular weight increment of INU-EDA and INU-FA with respect to the starting polymer confirmed the derivatization of inulin in turn with EDA and FA, although significant fragmentation of the polymeric backbone was not observed.

\subsection{Preparation and Characterization of INU-FA Coated} GNPs (Au@INU-FA). INU-FA-coated gold particles (Au@INU-FA) were prepared by means of the chemical adsorption of folate conjugate derivative of inulin onto GNPs surface. Taking advantage of the high affinity of gold for primary amines available in the conjugate backbone, a

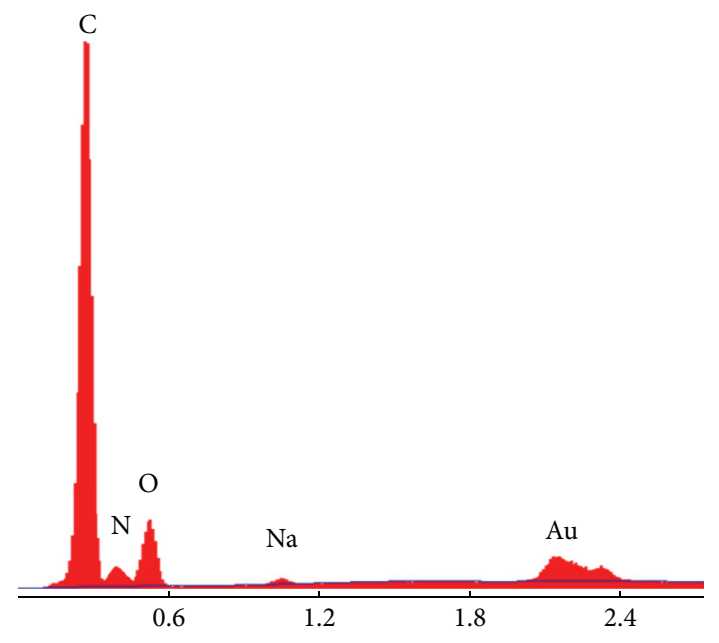

FIGURE 3: Energy dispersion X-ray chemical analysis of the surface of Au@INU-FA.

TABLE 1: Molecular weight $(\mathrm{Mw})$ and polydispersity $(\mathrm{Mw} / \mathrm{Mn})$ of inulin and its parent copolymers.

\begin{tabular}{lcc}
\hline Copolymers & $\mathrm{Mw}$ & $(\mathrm{Mw} / \mathrm{Mn})$ \\
\hline Inulin & 6319 & 1.27 \\
INU-EDA & 6504 & 1.31 \\
INU-FA & 6784 & 1.24 \\
\hline
\end{tabular}

stable polymeric coating able to confer aqueous stability to GNPs was obtained. The functionalization of GNPs surface was accomplished using an organic base (TEA) in such a manner to completely deprotonate the pendants amino groups of INU-FA, thus avoiding aggregation phenomena due to electrostatic interactions between the positive charged copolymer and the negative stained GNPs [29]. This simple method overcomes tedious processes that usually involved PEG as a prestabilizing agent to avoid undesired nanoparticle aggregation, as previously reported [30]. The aim of this coating was manifold. On one hand INU-FA may act as a colloidal hydrophilic coating stabilizing the dispersion of the nanosystem into aqueous media. Furthermore, it behaves as a targeting moiety for the cancer-targeted therapy. Finally, it might increase the loading of the drug by means of physical interactions.

The presence of polymer coating on GNPs surface was studied by qualitative energy dispersion X-ray elemental analysis (Figure 3), which showed the characteristic peaks of carbon, oxygen, and nitrogen, of the polymeric coating on GNPs surface.

The stability of the nanosystems in different aqueous media was studied by UV-Vis spectroscopy. As shown in Figure 4 , a tiny redshift of the LSPR band $(\sim 530 \mathrm{~nm})$ of Au@INU-FA without broadening was observed (Figure 4(a)), implying the absence of aggregation phenomena of the starting Au@citrate particles observed in TEM images (Figure 4(b)), in the whole media tested. Moreover, the UV profile of the drug-loaded nanosystem, without broadening in comparison with its parent systems, still confirmed the 

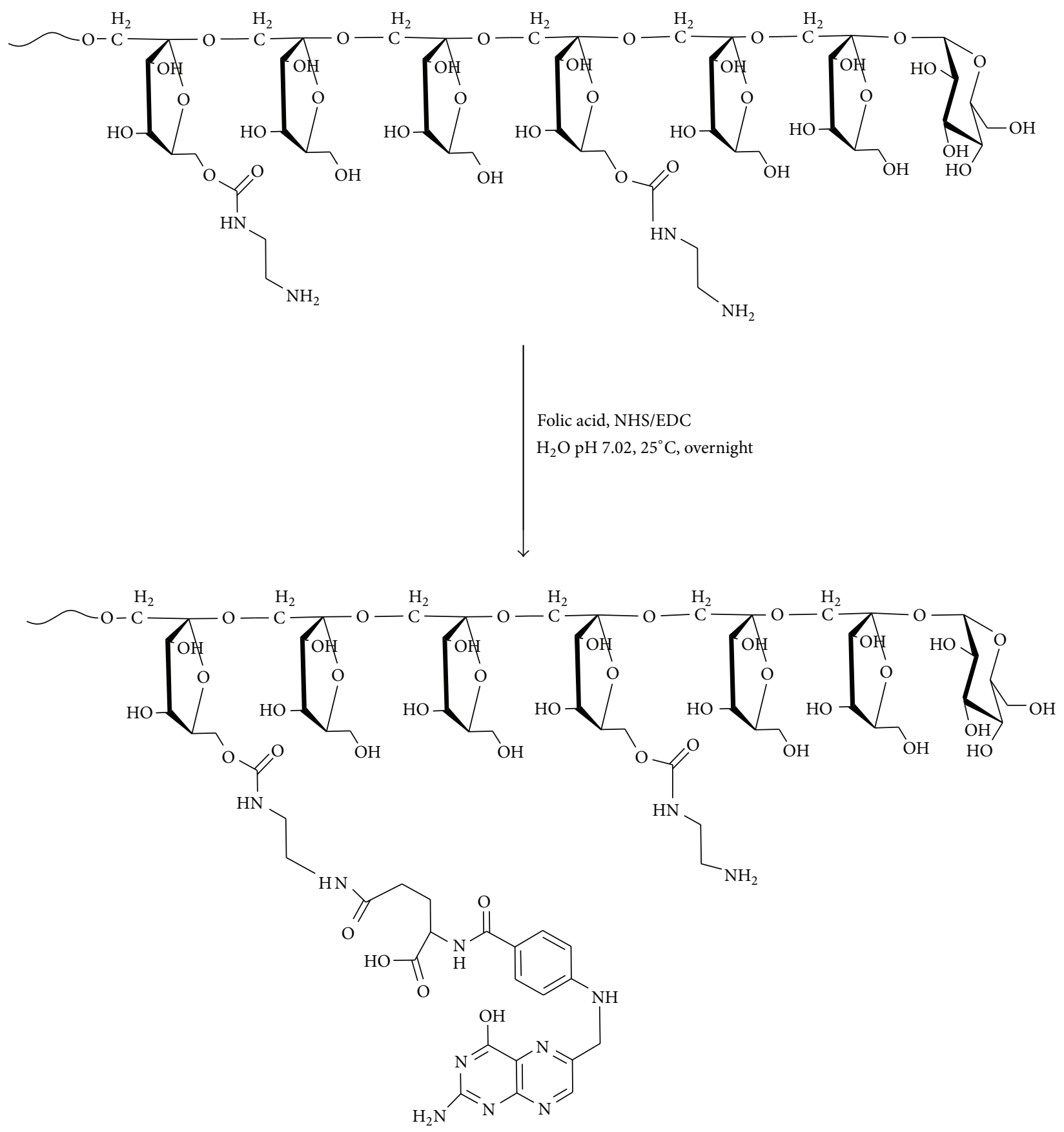

SCheme 1: Synthesis of INU-FA.

absence of aggregation after the drug loading processing, thus suggesting that doxorubicin was highly adsorbed onto the nanosystem surface.

DLS measurements supported the results obtained via UV-Vis spectroscopy, yielding an average hydrodynamic diameter of about $40 \mathrm{~nm}$ (Table 2). The obtained Au@INUFA nanoparticles, stabilized by the folate-inulin derivative, were able to load a suitable amount of the anticancer drug doxorubicin. Doxorubicin was selected as anticancer drug widely employed to treat leukemia and Hodgkin's lymphoma, as well as cancers of the bladder, breast, stomach, lung, ovaries, thyroid, soft tissue sarcoma, multiple myeloma, and others [31]. Drug loading was carried out adding aqueous INU-FA and doxorubicin hydrochloride solutions, previously treated with a molar excess of TEA, to the dispersion of Au@citrate [17, 20]. The drawing forces that allowed the loading of doxorubicin on Au@INU-FA/Doxo nanoparticles were both physical and chemical interactions. In particular, the weakly bound component is attributed to the formation of an electrostatic complex between protonated amine molecules of doxorubicin and surface-bound $\mathrm{AuCl}_{4}$ $/ \mathrm{AuCl}_{2}$ - ions, while the more strongly bound species can 


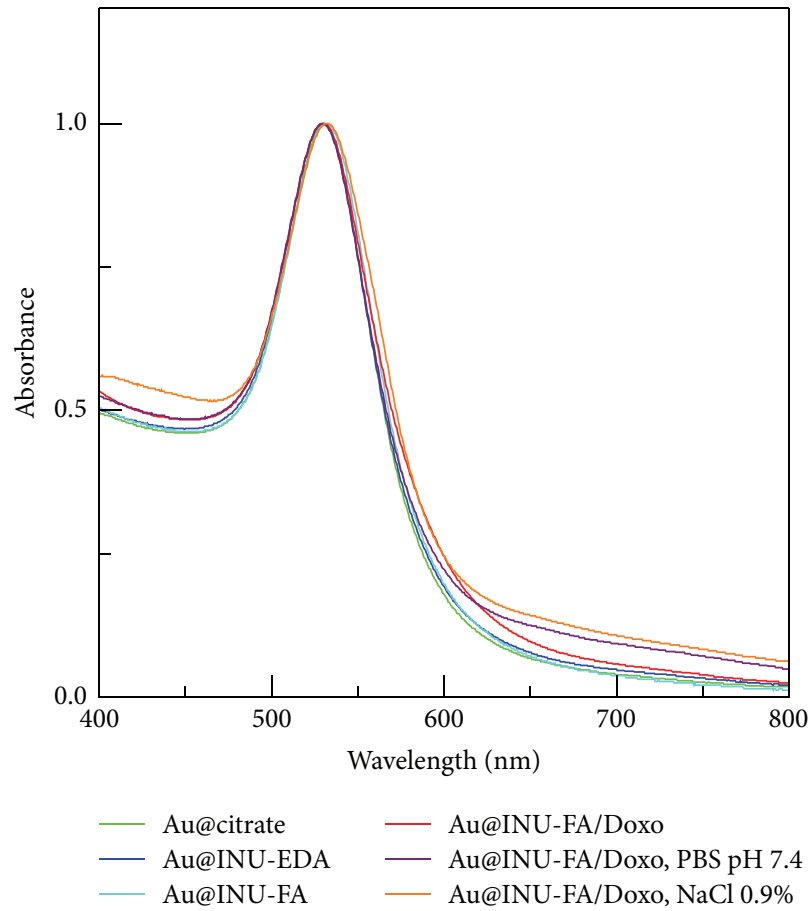

(a)

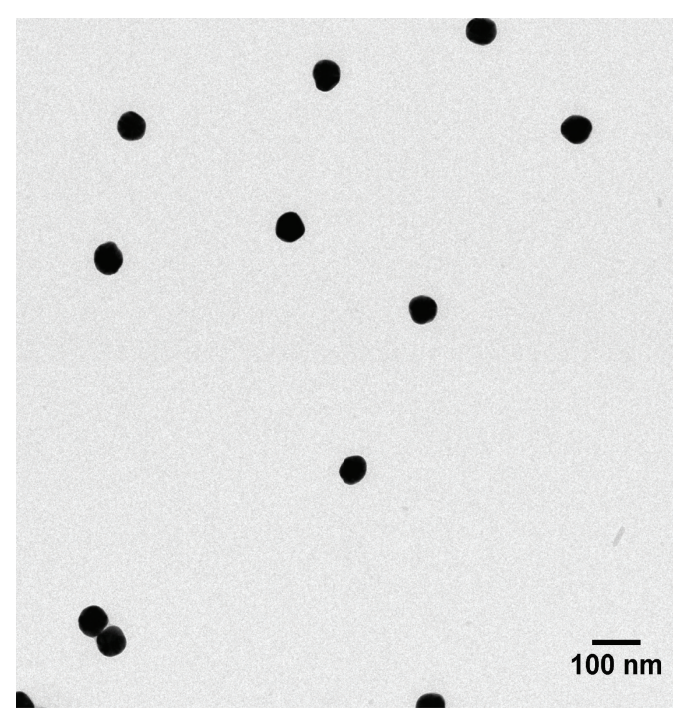

(b)

FIGURE 4: UV-Vis spectra of Au@citrate, Au@INU-EDA, Au@INU-FA, and Au@INU-FA/Doxo nanoparticles (a), showing a sharp LSPR band and the stability of Au@INU-FA/Doxo in different media: PBS pH 7.4, NaCl 0.9\% w/v, and Milli-Q water. TEM images of starting Au@citrate (b).

TABLE 2: DLS data, zeta potential values, and drug loading \% of Au@citrate, Au@INU-FA, and Au@INU-FA/Doxo samples in Milli-Q water $(0.1 \mathrm{mg} \mathrm{Au} / \mathrm{mL})$.

\begin{tabular}{|c|c|c|c|c|c|}
\hline Sample & $\begin{array}{l}Z \text { average } \\
(\mathrm{nm})\end{array}$ & PDI & $\begin{array}{l}\text { Zeta potential } \\
\qquad(\mathrm{mV})\end{array}$ & $\begin{array}{c}\text { Drug loading } \% \\
\text { (w/w) evaluated by } \\
\text { HPLC method }\end{array}$ & $\begin{array}{c}\text { Encapsulation } \\
\text { efficiency \% } \\
(w / w)\end{array}$ \\
\hline Au@citrate & 42.1 & 0.12 & -29.1 & - & - \\
\hline Au@INU-FA & 45.05 & 0.14 & -11.2 & - & - \\
\hline Au@INU-FA/Doxo & 40.7 & 0.21 & -10.7 & $18 \pm 2$ & $93 \pm 2$ \\
\hline
\end{tabular}




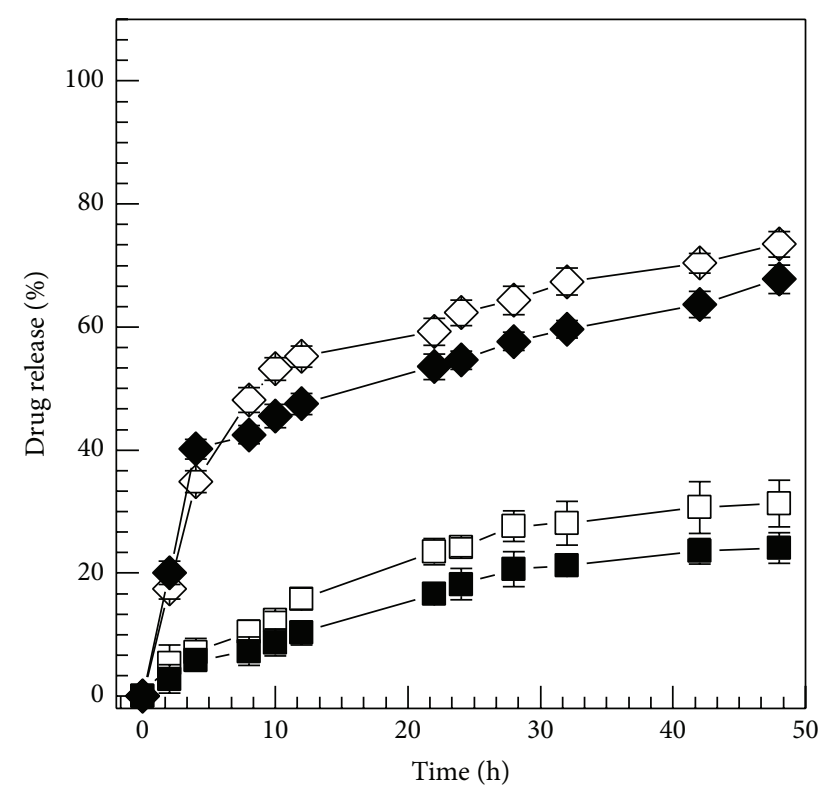

$-\square$ Au@INU-FA/Doxo PBS pH 5.5
$\checkmark$ Doxo free base PBS pH 5.5
$-\square$ - Au@INU-FA/Doxo PBS pH 7.4
- Doxo free base PBS pH 7.4

FIGURE 5: Percentage of released doxorubicin from Au@INUFA/Doxo NPs over time, incubated in PBS solutions at $\mathrm{pH} 7.4$ and $\mathrm{pH}$ 5.5. Doxorubicin not associated with NPs, in the free base $\left(-\mathrm{NH}_{2}\right)$ form, was used to determine normal doxorubicin release during dialysis.

be assigned to a complex of the form $\left[\mathrm{AuCl}\left(\mathrm{NH}_{2} \mathrm{R}\right)\right]$ [32]. Moreover, doxorubicin might interact somehow with the polymer backbone and with the aromatic rings of the folate groups. The amount of loaded drug, evaluated by HPLC analysis, was found to be $18 \% \mathrm{w} / \mathrm{w}$, with an encapsulation efficacy of approximately $90 \%$ (Table 2). DLS measurements carried out on Au@INU-FA/Doxo showed no significant variation in size and zeta potential compared to the unloaded system Au@INU-FA (Table 2).

3.3. Doxorubicin Release Studies. To evaluate the capability of Au@INU-FA/Doxo to release doxorubicin, release experiments were carried out in two media simulating different human body districts. In particular, PBS solution at pH 7.4, which mimics physiological medium, and $\mathrm{pH} 5.5$, mimicking endosomal and lysosomal environments, were used. The release experiments consisted in quantifying the amount of released doxorubicin in each release media, at fixed time points. In this experiment the control drug was used as free base, which is the form used for loading. In Figure 5 the cumulative release of doxorubicin, referred to the total amount of doxorubicin loaded into nanosystem, is shown as function of the incubation time. Au@INU-FA/Doxo proved capable of releasing doxorubicin for a prolonged period of time and without any initial "burst effect," for both $\mathrm{pH}$ values. For example, after $48 \mathrm{~h}$, approximately $18 \%$ and $23 \%$ of doxorubicin initially loaded in the system were slowly released in PBS at pH 7.4 and $\mathrm{pH}$ 5.5, respectively, indicating that a slow drug release rate, at both $\mathrm{pH}$ values, could be obtained even after reaching the tumor site [33].

3.4. In Vitro Biological Assays. The tumor-selective folatemediated cytotoxicity of the Au@INU-FA/Doxo here prepared was established by MTS assay on human breast cancer cell line (MCF7) and on human bronchial epithelial cell line (16 HBE). Cells were exposed to Au@INU-FA and Au@INU-FA/Doxo, as well as to free doxorubicin, for either $4 \mathrm{~h}, 24 \mathrm{~h}$, or $72 \mathrm{~h}$ at concentrations of $330,165,82.5,41.25$, and $20.62 \mu \mathrm{g} / \mathrm{mL}$ of $\mathrm{Au}^{0}$, corresponding to $100,50,25,12.5$, and $6.125 \mu \mathrm{M}$ of doxorubicin per well. Actually, Au@INUFA resulted without cytotoxic effect and no significant differences after $4 \mathrm{~h}, 24 \mathrm{~h}$, and $48 \mathrm{~h}$ incubation over the range of concentrations and time points tested for both cell lines, indicating an excellent cytocompatibility of the empty nanosystem even at the higher concentration tested (data not shown). Differently, free doxorubicin, used as positive control, resulted highly cytotoxic in both cell lines even at the lowest tested concentrations (Figure 6(a)) and did not greatly differentiate between cancer and noncancer cells, being even much more cytotoxic for 16HBE noncancer cell line. Interestingly, as shown in Figure 6(b), MCF7 cancer cell line was significantly more sensitive to the cytotoxic effect of Au@INU-FA/Doxo compared with epithelial cells over the three time points tested, as confirmed by the IC50 values which appear importantly lower for cancer cells (Table 3 ). These results can be explained with the ability of the folatetargeted system to be principally internalized by MCF7 cells, which express high levels of FRs, rather than in $16 \mathrm{HBE}$ noncancer cells, suggesting a folate-mediated endocytosis mechanism which allowed exerting a selective cytotoxic effect towards cancer cells.

To validate the hypothesis of a folate-mediated uptake of Au@INU-FA/Doxo system, a receptor blocking experiment on MCF7 cells followed by a MTS cell viability assay was carried out. In particular, MCF7 cells were first exposed to a high concentration of folic acid $(10 \mathrm{nM})$ to achieve the saturation of FRs [34] and then incubated with Au@INUFA/Doxo NPs at the same time points and concentration previously tested. Interestingly, the cytotoxic effect observed on the MCF7 cells with saturated FRs was significantly lower if compared with the one exhibited on MCF7 cells in the assay without folic acid pretreatment, as shown in Figure 7 and easily deducible by IC50 values reported in Table 3.

These findings can be explained by a significant enhancement of cell internalization of Au@INU-FA/Doxo when the FRs are available to bind the folate on targeted-NPs surface, thus enabling a folate-mediated endocytosis mechanism and a higher cytotoxic effect. The selectivity of the folatetargeted system towards FRs-positive cancer cells was further confirmed by quantitative uptake assay, measuring Doxo fluorescence intensity in MCF7 and $16 \mathrm{HBE}$ cell lysates upon treatment with Au@INU-FA/Doxo in cell cultures and with free Doxo $\mathrm{HCl}$ as positive control. As predicted by cytotoxicity assay, Au@INU-FA/Doxo taking advantage of the folate-mediated endocytosis was preferentially internalized into cancer cells already after 2 hours of incubation 


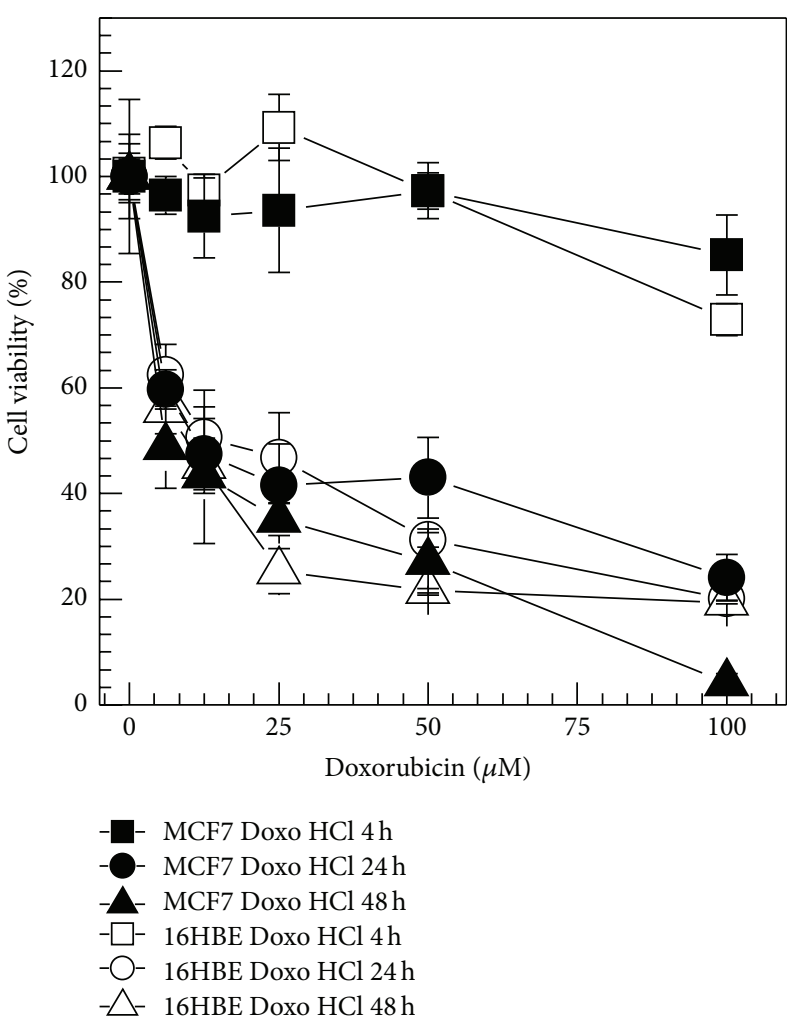

(a)

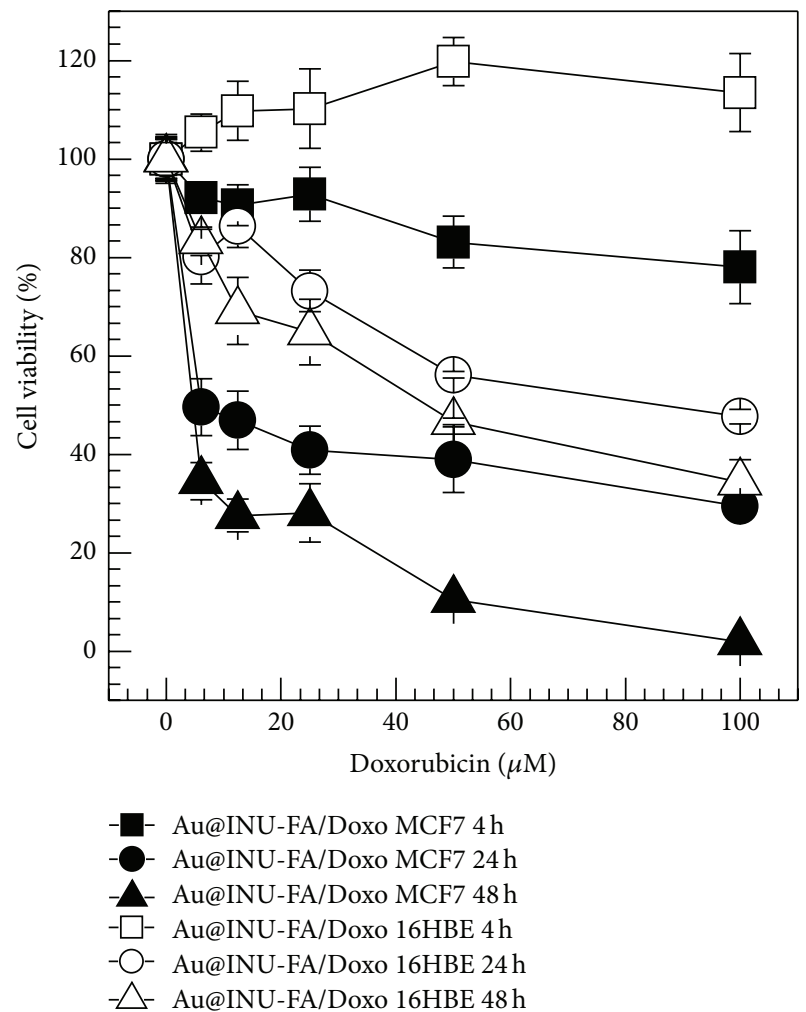

(b)

Figure 6: Cell cytotoxicity of free Doxo (a) and Au@INU-FA/Doxo NPs (b) on MCF7 and 16HBE cells after 4 h, 24 h, and 48 h of incubation time.

TABLE 3: IC50 values at $24 \mathrm{~h}$ and $48 \mathrm{~h}$ of Au@INU-FA/Doxo on MCF7 and 16HBE cell lines.

\begin{tabular}{lcc}
\hline Sample & $\mathrm{IC} 50^{24 \mathrm{~h}}(\mu \mathrm{M})$ & $\mathrm{IC50} 0^{48 \mathrm{~h}}(\mu \mathrm{M})$ \\
\hline Au@INU-FA/Doxo on MCF7 & 8.08 & 7.42 \\
Au@INU-FA/Doxo on 16HBE & 72.68 & 47.14 \\
Au@INU-FA/Doxo on MCF7 + FRs blocked & 36.75 & 13.86 \\
Free Doxo on MCF7 & 15.79 & 9.41 \\
Free Doxo on 16HBE & 22.89 & 9.60 \\
\hline
\end{tabular}

time, as demonstrated by the significantly higher doxorubicin amount into MCF7 with respect to $16 \mathrm{HBE}$ cells (Figure 8(b)), thus enabling a higher and selective cytotoxic effect towards cancer cells. Instead, free Doxo $\mathrm{HCl}$ not entrapped into nanoparticles, diffuses in both cell types (MCF7 and 16HBE) being not able to discriminate between cancer and noncancer cells. Moreover, negligible differences in uptake are visible between MCF7 with blocked and not blocked FRs. The lack of selectivity of doxorubicin, when delivered without a NP carrier, in noncancer cells at such short time points, could explain doxorubicin's toxicity towards normal tissues and cells.

The internalization of Au@INU-FA/Doxo into cancer cells was also qualitatively revealed by fluorescence microscopy of MCF7 cell line (Figure 9). Images obtained after exposure of cells to NPs for $1 / 2 \mathrm{~h}, 1 \mathrm{~h}$, and $2 \mathrm{~h}$ showed that doxorubicin was progressively accumulated in the cytoplasm of the cells, as a consequence of the Au@INU-FA/Doxo NPs internalization.

\section{Conclusions}

In this study, we reported a novel cytocompatible folatetargeted gold-based nanosystem, namely, Au@INU-FA, that can easily load doxorubicin while showing excellent physiochemical stability. The use of biocompatible and biodegradable inulin-folate conjugate used as coating agent was found to give two important advantages: an improvement in the physical stability of the system in physiological mimicking media, as proved by UV-Vis spectroscopy, and an increased anticancer activity towards MCF7 cancer cells by means of folate-mediated uptake. Au@INU-FA/Doxo has proved capable of loading $18 \%$ of doxorubicin guaranteeing a prolonged drug release in different simulated media. Finally, the 


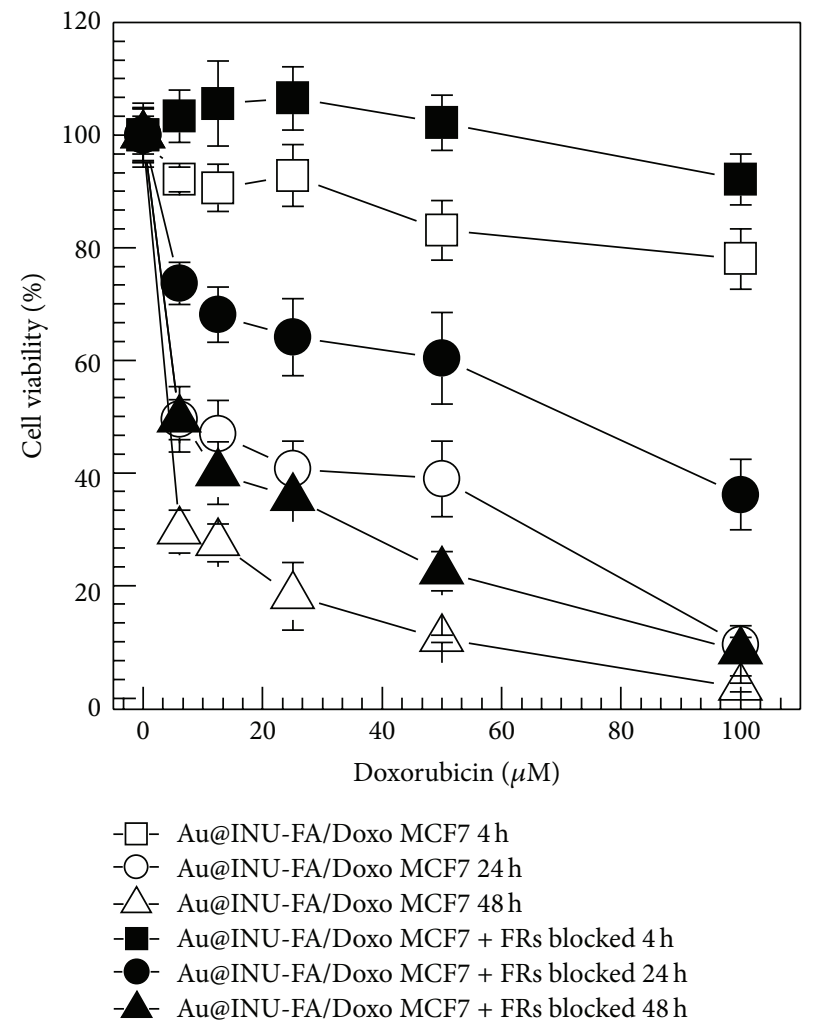

FIGURE 7: Cell cytotoxicity of Au@INU-FA/Doxo NPs on MCF7 cells after FRs-blocking experiment (MCF7 + FRs blocked) and without folic acid pretreatment (MCF7). Incubation times were $4 \mathrm{~h}, 24 \mathrm{~h}$, and $48 \mathrm{~h}$.

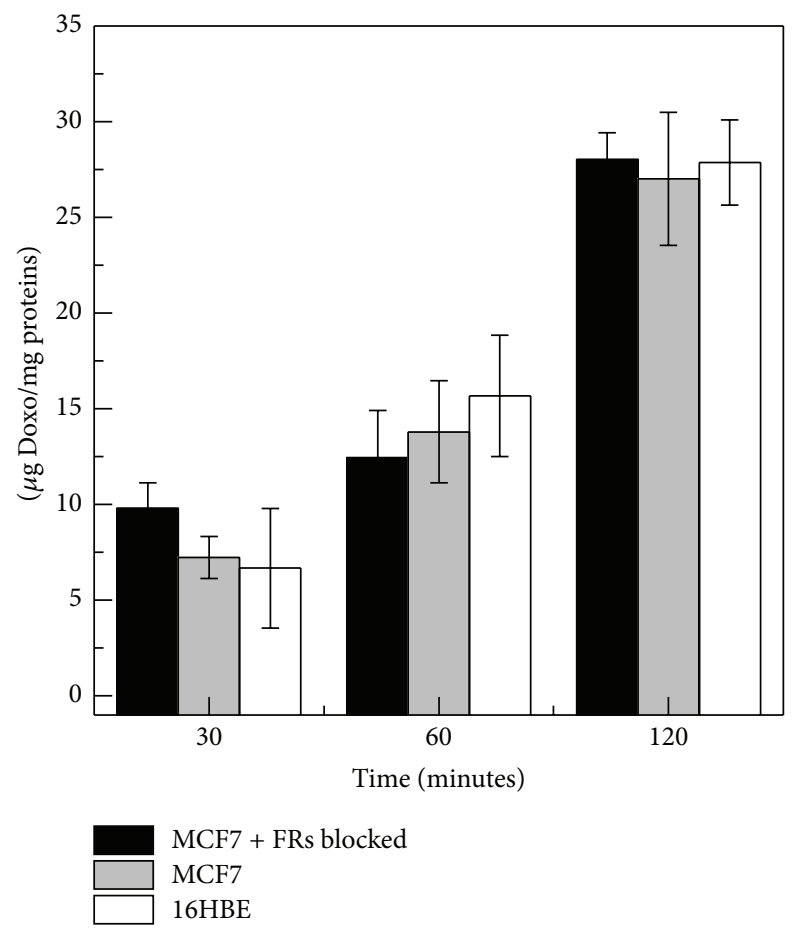

(a)

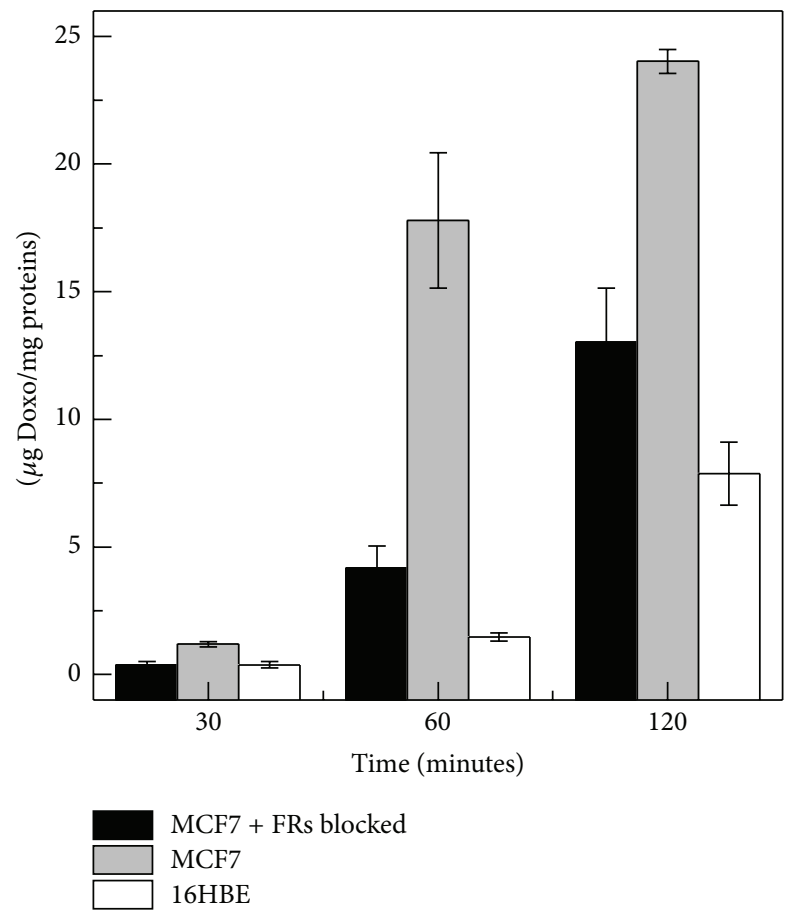

(b)

FIGURE 8: Quantitative uptake analysis of free Doxo $\mathrm{HCl}$ (a) and Au@INU-FA/Doxo (b) in MCF7 and 16 HBE cell lines after FRs-blocking experiment (MCF7 + FRs blocked) and without folic acid pretreatment (MCF7; 16 HBE). Incubation times were 30, 60, and 120 minutes. 

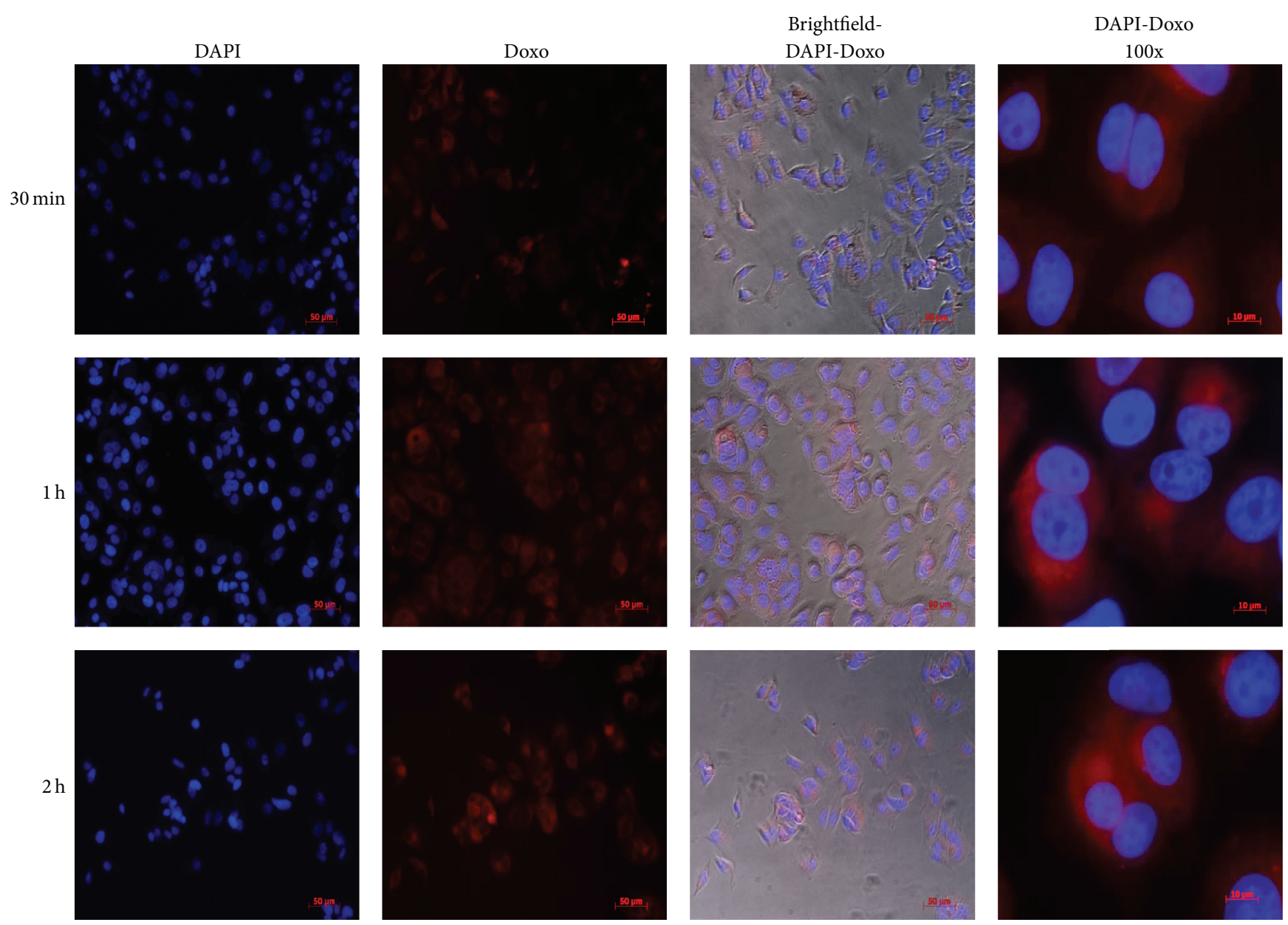

Figure 9: Fluorescence microscopy images of MCF7 cells incubated with Au@INU-FA/Doxo. Incubation times were 1/2 h, 1h, and $2 \mathrm{~h}$. Doxorubicin is visualized in red; cell nuclei were stained with DAPI (blue). Magnification was 20x.

system exhibited a preferential accumulation into cancer cells rather than non-cancer cells. We demonstrated differences in particle uptake between MCF7 cancer and 16HBE non cancer cell lines. Our findings offer advantageous therapeutic effects regarding increased anticancer activity and reduced non-specific cytotoxicity to surrounding healthy tissues, supporting the possible selection of Au@INU-FA/Doxo as a promising candidate for future in vivo evaluations.

\section{Competing Interests}

The authors report no competing interests in this work.

\section{Acknowledgments}

The authors thank the MIUR and the University of Palermo for funding.

\section{References}

[1] B. W. Stewart and C. P. Wild, World Cancer Report, 2014.

[2] J. A. Webb and R. Bardhan, "Emerging advances in nanomedicine with engineered gold nanostructures," Nanoscale, vol. 6, no. 5, pp. 2502-2530, 2014.
[3] H. Maeda, "The enhanced permeability and retention (EPR) effect in tumor vasculature: the key role of tumor-selective macromolecular drug targeting," Advances in Enzyme Regulation, vol. 41, pp. 189-207, 2001.

[4] T. M. Allen, "Ligand-targeted therapeutics in anticancer therapy," Nature Reviews Cancer, vol. 2, no. 10, pp. 750-763, 2002.

[5] J. S. Ross, D. P. Schenkein, R. Pietrusko et al., "Targeted therapies for cancer 2004," American Journal of Clinical Pathology, vol. 122, no. 4, pp. 598-609, 2004.

[6] W. J. Gradishar, S. Tjulandin, N. Davidson et al., "Phase III trial of nanoparticle albumin-bound paclitaxel compared with polyethylated castor oil-based paclitaxel in women with breast cancer," Journal of Clinical Oncology, vol. 23, no. 31, pp. 77947803,2005

[7] T.-Y. Kim, D.-W. Kim, J.-Y. Chung et al., "Phase I and pharmacokinetic study of Genexol-PM, a Cremophor-free, polymeric micelle-formulated paclitaxel, in patients with advanced malignancies," Clinical Cancer Research, vol. 10, no. 11, pp. 3708-3716, 2004.

[8] J. F. Kukowska-Latallo, K. A. Candido, Z. Cao et al., "Nanoparticle targeting of anticancer drug improves therapeutic response in animal model of human epithelial cancer," Cancer Research, vol. 65 , no. 12 , pp. 5317-5324, 2005. 
[9] M. Markman, "Pegylated liposomal doxorubicin in the treatment of cancers of the breast and ovary," Expert Opinion on Pharmacotherapy, vol. 7, no. 11, pp. 1469-1474, 2006.

[10] P. Singh, G. Destito, A. Schneemann, and M. Manchester, "Canine parvovirus-like particles, a novel nanomaterial for tumor targeting," Journal of Nanobiotechnology, vol. 4, article 2, 2006.

[11] G. Pastorin, W. Wu, S. Wieckowski et al., "Double functionalisation of carbon nanotubes for multimodal drug delivery," Chemical Communications, no. 11, pp. 1182-1184, 2006.

[12] P. Ghosh, G. Han, M. De, C. K. Kim, and V. M. Rotello, "Gold nanoparticles in delivery applications," Advanced Drug Delivery Reviews, vol. 60, no. 11, pp. 1307-1315, 2008.

[13] M. Grzelczak and L. M. Liz-Marzán, "Colloidal nanoplasmonics: from building blocks to sensing devices," Langmuir, vol. 29, no. 15, pp. 4652-4663, 2013.

[14] D. Kim, S. Park, H. L. Jae, Y. J. Yong, and S. Jon, “Antibiofouling polymer-coated gold nanoparticles as a contrast agent for in vivo X-ray computed tomography imaging," Journal of the American Chemical Society, vol. 129, no. 24, pp. 7661-7665, 2007.

[15] O. S. Muddineti, B. Ghosh, and S. Biswas, "Current trends in using polymer coated gold nanoparticles for cancer therapy," International Journal of Pharmaceutics, vol. 484, no. 1-2, pp. 252267, 2015.

[16] M. Licciardi, C. Scialabba, G. Cavallaro, C. Sangregorio, E. Fantechi, and G. Giammona, "Cell uptake enhancement of folate targeted polymer coated magnetic nanoparticles," Journal of Biomedical Nanotechnology, vol. 9, no. 6, pp. 949-964, 2013.

[17] A. Li Volsi, D. Jimenez De Aberasturi, M. Henriksen-Lacey, G. Giammona, M. Licciardi, and L. M. Liz-Marzán, "Inulin coated plasmonic gold nanoparticles as a tumor-selective tool for cancer therapy," Journal of Materials Chemistry B, vol. 4, no. 6, pp. 1150-1155, 2016.

[18] M. Licciardi, A. Li Volsi, C. Sardo, N. Mauro, G. Cavallaro, and G. Giammona, "Inulin-ethylenediamine coated SPIONs magnetoplexes: a promising tool for improving siRNA delivery," Pharmaceutical Research, vol. 32, no. 11, pp. 3674-3687, 2015.

[19] N. Mauro, S. Campora, C. Scialabba et al., "Self-organized environment-sensitive inulin-doxorubicin conjugate with a selective cytotoxic effect towards cancer cells," RSC Advances, vol. 5, no. 41, pp. 32421-32430, 2015.

[20] M. Licciardi, C. Scialabba, C. Sardo, G. Cavallaro, and G. Giammona, "Amphiphilic inulin graft co-polymers as selfassembling micelles for doxorubicin delivery," Journal of Materials Chemistry B, vol. 2, no. 27, pp. 4262-4271, 2014.

[21] G. Pitarresi, G. Tripodo, D. Triolo, C. Fiorica, and G. Giammona, "Inulin vinyl sulfone derivative cross-linked with bis-amino PEG: new materials for biomedical applications," Journal of Drug Delivery Science and Technology, vol. 19, no. 6, pp. 419-423, 2009.

[22] F. S. Palumbo, C. Fiorica, M. Di Stefano et al., "In situ forming hydrogels of hyaluronic acid and inulin derivatives for cartilage regeneration," Carbohydrate Polymers, vol. 122, pp. 408-416, 2015.

[23] D. Mandracchia, G. Tripodo, A. Latrofa, and R. Dorati, "Amphiphilic inulin-d- $\alpha$-tocopherol succinate (INVITE) bioconjugates for biomedical applications," Carbohydrate Polymers, vol. 103, no. 1, pp. 46-54, 2014.

[24] D. Mandracchia, N. Denora, M. Franco, G. Pitarresi, G. Giammona, and G. Trapani, "New biodegradable hydrogels based on inulin and $\alpha, \beta$-polyaspartylhydrazide designed for colonic drug delivery: in vitro release of glutathione and oxytocin," Journal of Biomaterials Science, Polymer Edition, vol. 22, no. 1-3, pp. 313-328, 2011.

[25] G. Cavallaro, M. Licciardi, G. Pitarresi, and G. Giammona, "Folate-mediated targeting of polymers as components of colloidal drug delivery systems," in Handbook of Drug Targeting and Monitoring, vol. 6, pp. 165-178, Nova Science Publishers, New York, NY, USA, 2010.

[26] R. Pierson, L. Kyubae, P. Soo-Young, and K. Inn-Kyu, “Targeted images of KB cells using folate-conjugated gold nanoparticles," Nanoscale Research Letters, vol. 10, article 5, 2015.

[27] H. Banu, D. K. Sethi, A. Edgar et al., "Doxorubicin loaded polymeric gold nanoparticles targeted to human folate receptor upon laser photothermal therapy potentiates chemotherapy in breast cancer cell lines," Journal of Photochemistry and Photobiology B: Biology, vol. 149, pp. 116-128, 2015.

[28] N. G. Bastús, J. Comenge, and V. Puntes, "Kinetically controlled seeded growth synthesis of citrate-stabilized gold nanoparticles of up to $200 \mathrm{~nm}$ : aize focusing versus ostwald ripening," Langmuir, vol. 27, no. 17, pp. 11098-11105, 2011.

[29] P. C. Griffiths, N. Mauro, D. M. Murphy et al., "Self-assembled PAA-based nanoparticles as potential gene and protein delivery systems," Macromolecular Bioscience, vol. 13, no. 5, pp. 641-649, 2013.

[30] A. B. Serrano-Montes, D. J. de Aberasturi, J. Langer et al., "A general method for solvent exchange of plasmonic nanoparticles and self-assembly into SERS-active monolayers," Langmuir, vol. 31, no. 33, pp. 9205-9213, 2015.

[31] A. Brayfield, Doxorubicin. Martindale: The Complete Drug Reference, Pharmaceutical Press, 2013.

[32] A. Kumar, S. T. Mandal, P. R. Selvakannan, R. Pasricha, A. B. Mandale, and M. Sastry, "Investigation into the interaction between surface-bound alkylamines and gold nanoparticles," Langmuir, vol. 19, no. 15, pp. 6277-6282, 2003.

[33] M. E. Davis, Z. Chen, and D. M. Shin, "Nanoparticle therapeutics: an emerging treatment modality for cancer," Nature Reviews Drug Discovery, vol. 7, no. 9, pp. 771-782, 2008.

[34] Z. Tang, D. Li, H. Sun, X. Guo, Y. Chen, and S. Zhou, "Quantitative control of active targeting of nanocarriers to tumor cells through optimization of folate ligand density," Biomaterials, vol. 35, no. 27, pp. 8015-8027, 2014. 

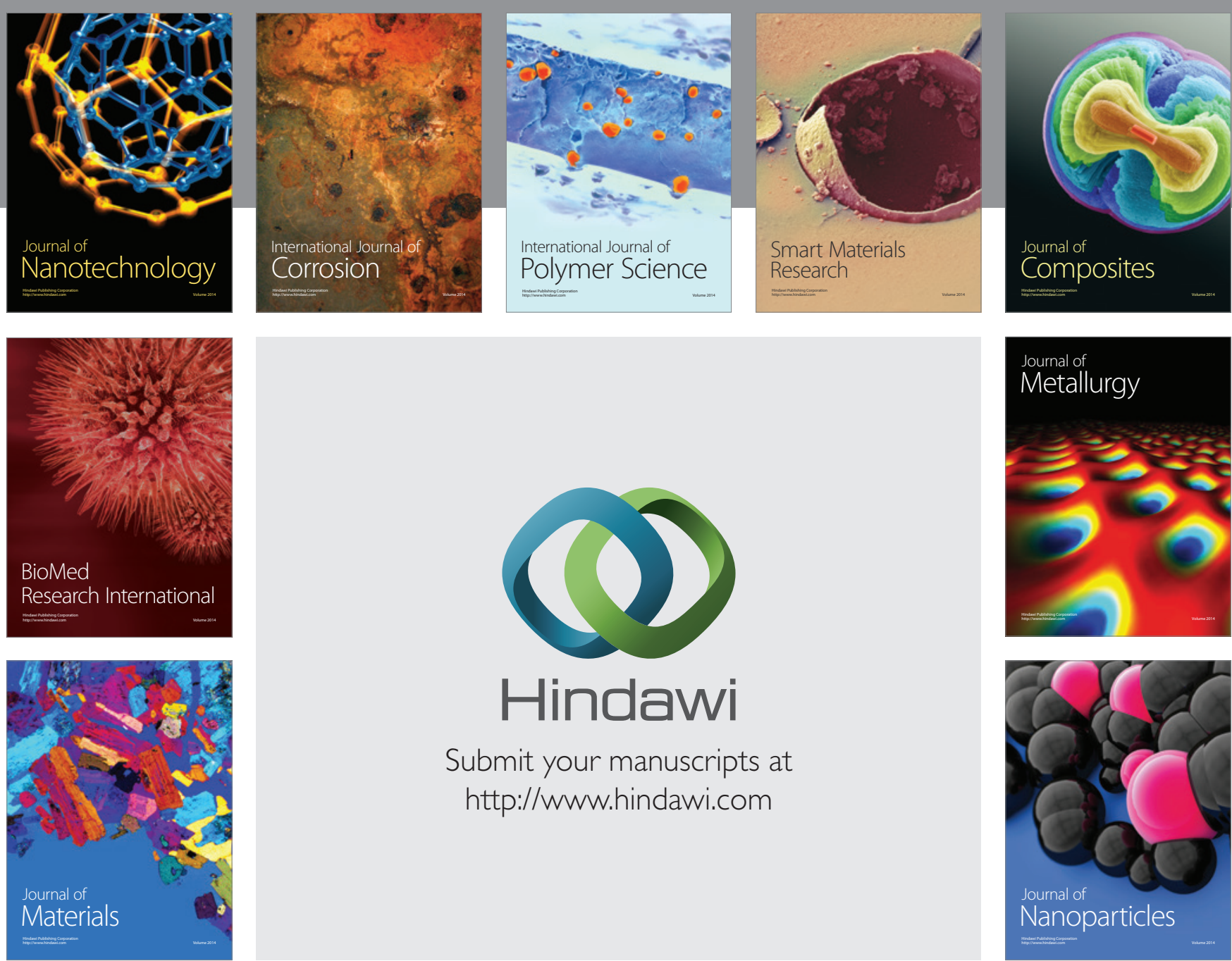

\section{Hindawi}

Submit your manuscripts at

http://www.hindawi.com

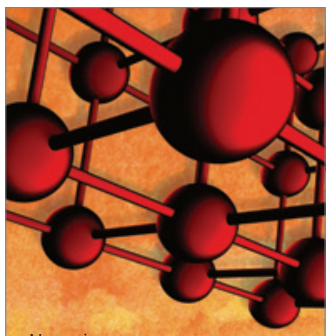

Materials Science and Engineering
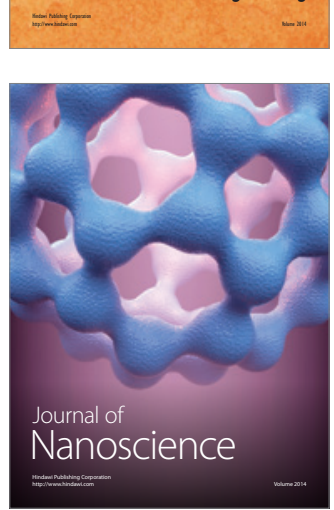
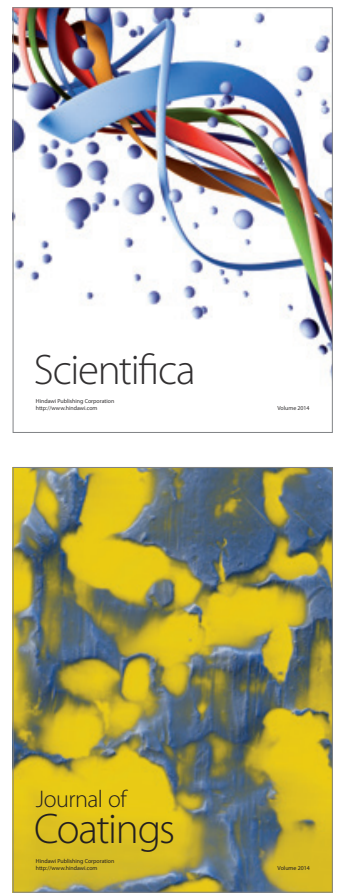
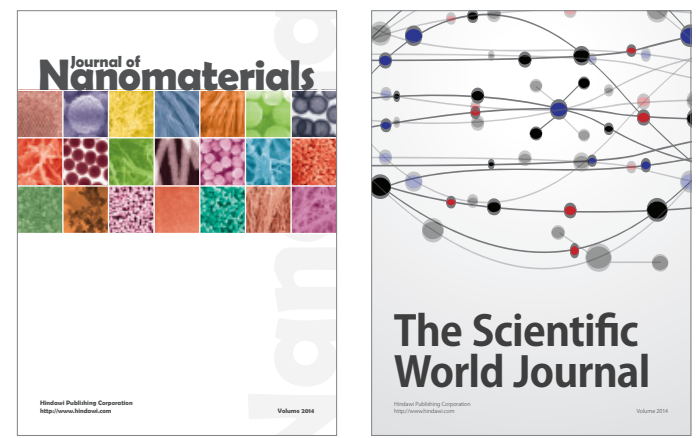

The Scientific World Journal
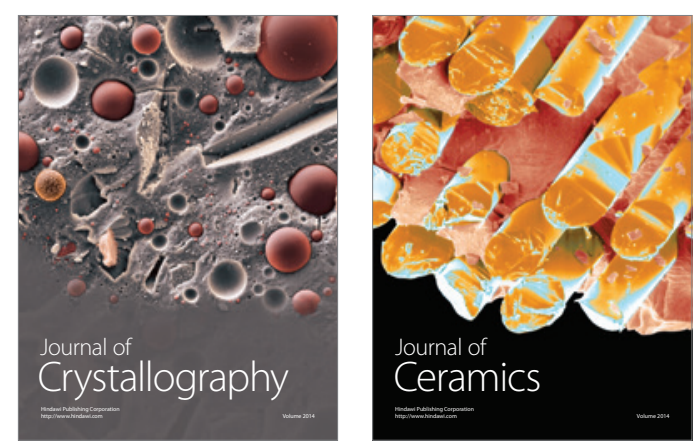
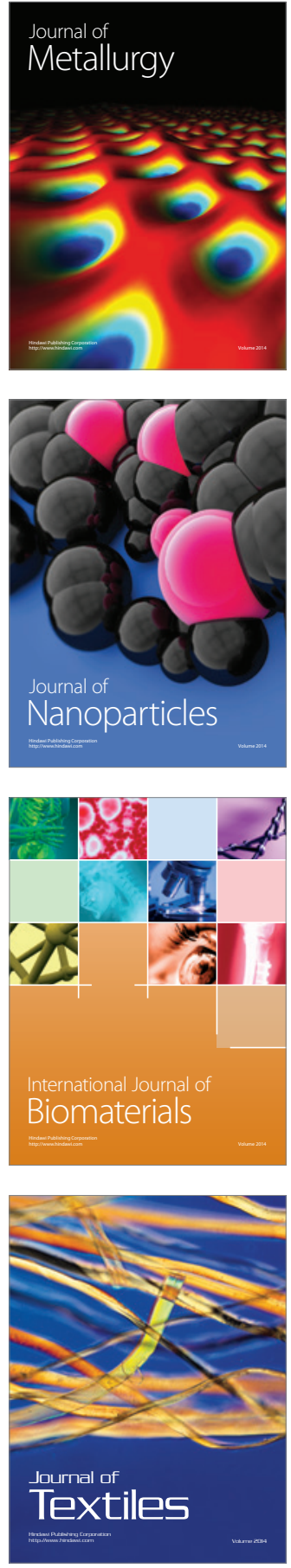